\title{
Genetic and metabolic aspects of androstenone and skatole deposition in pig adipose tissue: A review (Open Access publication)
}

\author{
Annie Robic ${ }^{1 *}$, Catherine LARzUL ${ }^{2}$, Michel BonNEAU $^{3}$ \\ ${ }^{1}$ INRA, UMR 444 de Génétique cellulaire, BP52627, 31326 Castanet-Tolosan, France \\ ${ }^{2}$ INRA, UR337 Station de génétique quantitative et appliquée, 78352 Jouy-en-Josas, France \\ ${ }^{3}$ INRA, UMR1079 Systèmes d'élevage, nutrition animale et humaine, INRA-Agrocampus \\ Rennes, Domaine de la Prise, 35590 Saint-Gilles, France
}

(Received 4 May 2007; accepted 25 July 2007)

\begin{abstract}
High levels of androstenone and skatole in fat tissues are considered the primary causes of boar taint, an unpleasant odour and flavour of the meat from non-castrated male pigs. The aim of this article is to review our current knowledge of the biology and genetic control of the accumulation of androstenone and skatole in fat tissue. Two QTL mapping studies have shown the complexity of the genetic control of these traits. During the last ten years, several authors have taken a more physiological approach to investigate the involvement of genes controlling the metabolism of androstenone and skatole. Although some authors have claimed the identification of candidate genes, it is more appropriate to talk about target genes. This suggests that genes affecting androstenone and skatole levels will have to be sought for among specific or non-specific transcription factors interacting with these target genes.
\end{abstract}

androstenone / skatole / pig / boar taint / QTL

\section{INTRODUCTION}

Castration of male pigs is a common practice, which reduces aggressive behaviour, makes animal management easier and reduces the occurrence of boar taint, a strong perspiration-like and urine-like unpleasant odour and flavour released by heating or cooking boar meat. Boar taint is primarily derived from the accumulation of androstenone and skatole in fat tissue [30,49]. This subject has already been reviewed by Claus et al. [9]), and Bonneau [5] but our present

*Corresponding author: annie.robic@toulouse.inra.fr

Article published by EDP Sciences and available at http://www.gse-journal.org or http://dx.doi.org/10.1051/gse:2007040 
study will focus on the progress made in understanding the genetic aspects of boar taint.

Androstenone is a steroid, which causes a pronounced urine-like odour and flavour in meat. There is a large variation in the consumers' sensitivity to androstenone i.e. some consumers are able to detect very low concentrations while others are anosmic to it [51]. Androstenone is formed in the testis, together with the steroid hormones, androgens and estrogens, and its production level depends on the sexual maturation $[8,16]$. The second contributors to boar taint are indoles, especially 3-methyl indole or skatole. Almost all the consumers are sensitive to skatole, which gives meat a faecal-like odour and flavour [50]. Indoles are produced by bacteria in the colon, from the breakdown of the amino-acid tryptophan [18]. The reason why high levels of skatole in fat tissue exist in some intact pig males, but not in castrates and gilts, is not fully understood.

The genetic determinism of androstenone and skatole levels has been investigated primarily through the estimation of genetic parameters. In the literature, the average heritability value of androstenone levels is high $\left(h^{2}=0.56\right)$, ranging from 0.25 to 0.88 [35] with recent estimated values in the same range $[36,48]$. Skatole levels show medium heritability values ranging from 0.19 to $0.54[31,45]$. In addition, it has been suggested that a major gene controlling the level of androstenone in fat is segregating in a Large White population [15] and that another major gene is affecting the skatole level [27]. Tajet et al. [45] have reported a positive genetic correlation between skatole and androstenone levels (0.36-0.62).

The aim of this review is to carry out an inventory of approaches undertaken to understand the genetic factors involved in boar taint. First, we shall describe how several teams have carried out the characterization of QTL, revealing the particular complexity of these traits. Second, we shall present the studies aimed at characterizing the metabolic pathways involved and the physiological methodologies used to identify candidate genes. In order to better confront the two approaches, we provide in Table I data on the genes cited in this review with their putative position in the pig genome deduced from their location on the human physical map (http://www.ensembl.org/Homo_sapiens/index.html) and the comparative pig/human map established by Robic et al. [34] (http://www2.toulouse.inra.fr/lgc/pig/msat/). Lastly, we shall give some perspectives on the use of these various strategies to identify genes involved in such complex traits. These genes often belong to a multigenic family and are located in a cluster. However, since the number of porcine genes included in a cluster can differ from that in man (Tab. I), the correct identification of which 
Review of genetic aspects of boar taint

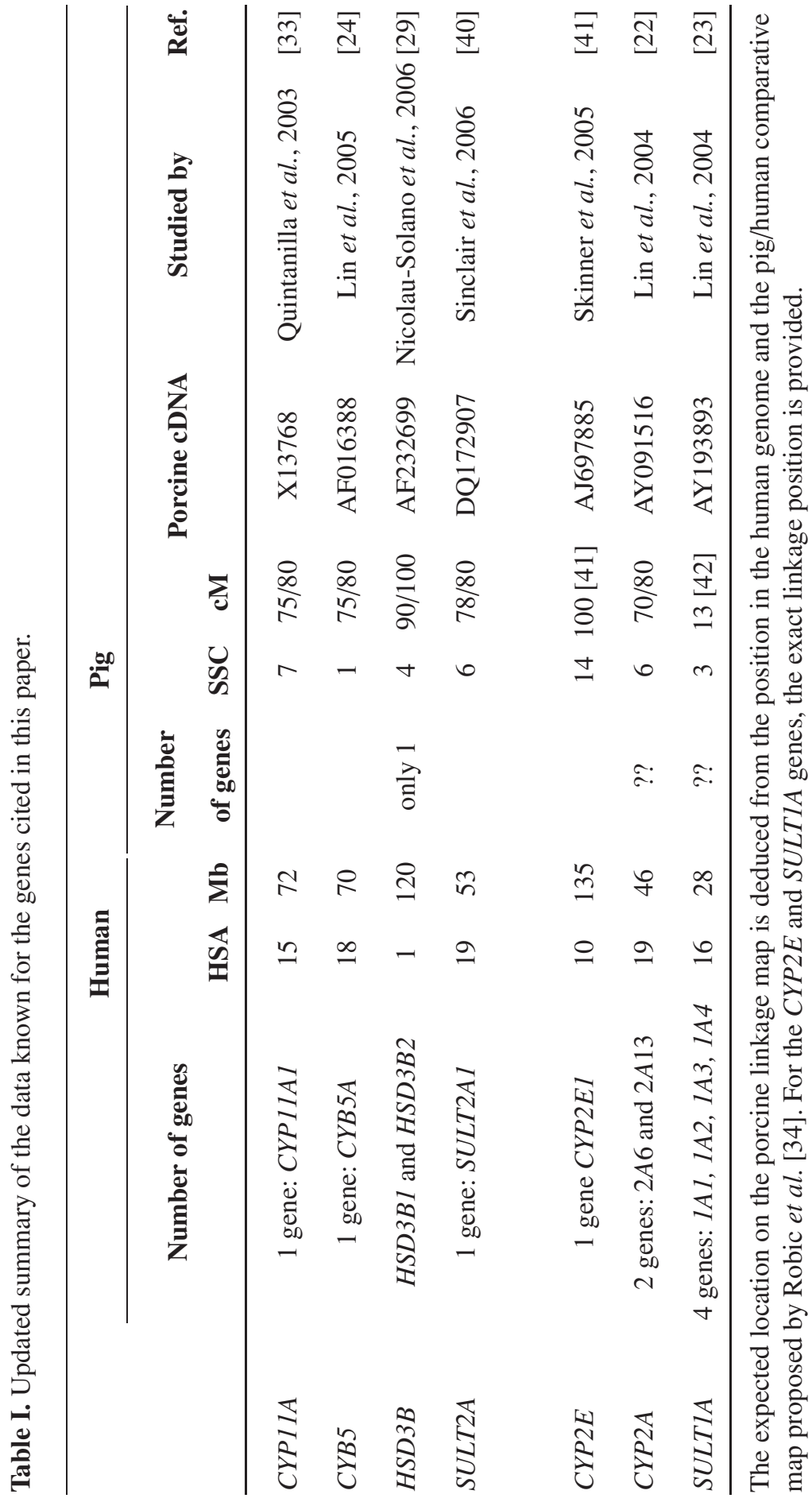


gene the authors have worked on is not always obvious. Thus, we have chosen not to attribute numbers to the porcine genes.

\section{DETECTION OF QUANTITATIVE TRAIT LOCI (QTL)}

The first QTL analysis of androstenone levels in fat was performed on a three-generation experimental cross between Large White (LW) and Meishan (MS) pig breeds [33]. The level of androstenone in fat was measured on F2 generation boars aged 100, 120, 140 and 160 days and on individuals slaughtered at around $80 \mathrm{~kg}$ live weight. Four major QTL were detected on pig chromosomes SSC3, SSC7, SSC13 and SSC14, which explained respectively 7 to $11 \%, 11$ to $15 \%, 4$ to $9 \%$ and 6 to $8 \%$ of the phenotypic variance. Two minor QTL were characterized on SSC4 and SSC9, which explained 4 to $7 \%$ of the variance. Some QTL were found to have a significant (SSC6) or suggestive (SSC10, SSC11, SSC18) effect on androstenone level only at one stage i.e. 100 or 120 days of age. In slaughtered individuals, the only QTL detected were the QTL on SSC7 and the suggestive QTL on SSC14. High androstenone levels were associated with alleles from the Meishan breed, except on SSC7. The variation in the number and position of QTL according to age indicates that the biochemical mechanism of this trait is complex and involves numerous genes.

The second QTL analysis [21] was performed on a similar experimental F2 population and androstenone levels in fat were determined only at slaughter (85 kg live weight). Five QTL were detected for androstenone on SSC2, SSC4 (mostly significant because of a dominant effect), SSC6, SSC7, and SSC9, which explained respectively 7.1, 8.6, 7.5, 6.2 and $6.2 \%$ of the phenotypic variance. Additionally, QTL for androstenone score assessed by a sensory panel, were detected on SSC13 and SSC14, but the authors speculated that the androstenone score was more related to skatole or indole levels than to androstenone level. In both studies, the power to detect QTL was limited by the size of the populations. The French study [33] included 485 intact males and only one QTL was detected at slaughter. The British study [21] was performed with only 178 boars and authors characterized five androstenone QTL at slaughter. Although the two F2 populations were quite similar, only the QTL on SSC7 was detected in both studies at close locations $(64$ and $70 \mathrm{cM})$ with a Meishan allele associated with a lower androstenone level.

Lee et al. [21] and Bidanel et al. [4], worked on subgroups of the Large White $\times$ Meishan pig population used in the French study [33] and measured skatole and indole accumulation in fat at slaughter (80-85 kg live weight). 
Each team identified QTL on different chromosomes i.e. for skatole SSC6, SSC13 and SSC14 [21] versus SSC7, SSC12 and SSCX [4] and for indole SSC13 and SSC14 [21] versus SSC2, SSC6 and SSC7 [4]. The results of the assessment of lean and fat samples by a sensory panel [21] resulted in the detection of a QTL on SSC14 for skatole scores, half way between the QTL identified for skatole and indole levels. In conclusion, although the population sizes, genotypes and measurements were similar, the subsets of QTL identified were completely different.

A third study on boar taint QTL was carried out on a Landrace outbred population [48]. Androstenone and skatole concentrations in fat were determined in 217 intact boars. Only 10 regions of the genome, chosen on the basis of previously detected QTL for growth and fatness, were scanned with two microsatellite markers. Except for SSC3, 4, 6 and 7, none of the other regions studied included locations where boar taint QTL had previously been described. The authors identified only one QTL for skatole on SSC6 in a region where a QTL had been previously detected for androstenone [21].

\section{GENES INVOLVED IN THE METABOLISM OF ANDROSTENONE}

\subsection{Androstenone synthesis and metabolism}

Together with other 16-androstene steroids, androstenone (5 $\alpha$-androst-16en-3-one) is synthesized in the testis from pregnenolone [16,19,20], in relation with sexual development, and stored in fat tissue because of its lipophilic properties. The pathways of the synthesis of androstenone in the testis are presented in Figure 1, drawn according to Brooks and Pearson [6] and to which we have added the two steps of degradation, which are now clearly identified: phase I i.e. metabolism by hydrogenation and phase II i.e. metabolism by sulfoconjugation in the testis or in the liver [14,38,39]. Therefore, in theory, high levels of androstenone in fat can be ascribed to a high intensity of testicular synthesis or/and a low intensity of liver degradation or/and a low intensity of testicular metabolism.

\subsection{Genes involved in the testicular synthesis of androstenone}

The initial step in steroidogenesis is the formation of pregnenolone from the cleavage of the side chain of cholesterol, catalysed by the enzyme CYP11A (Fig. 1). The sequence of the mRNA for porcine CYPl1Al is available (Tab. I) 
A. Robic et al.
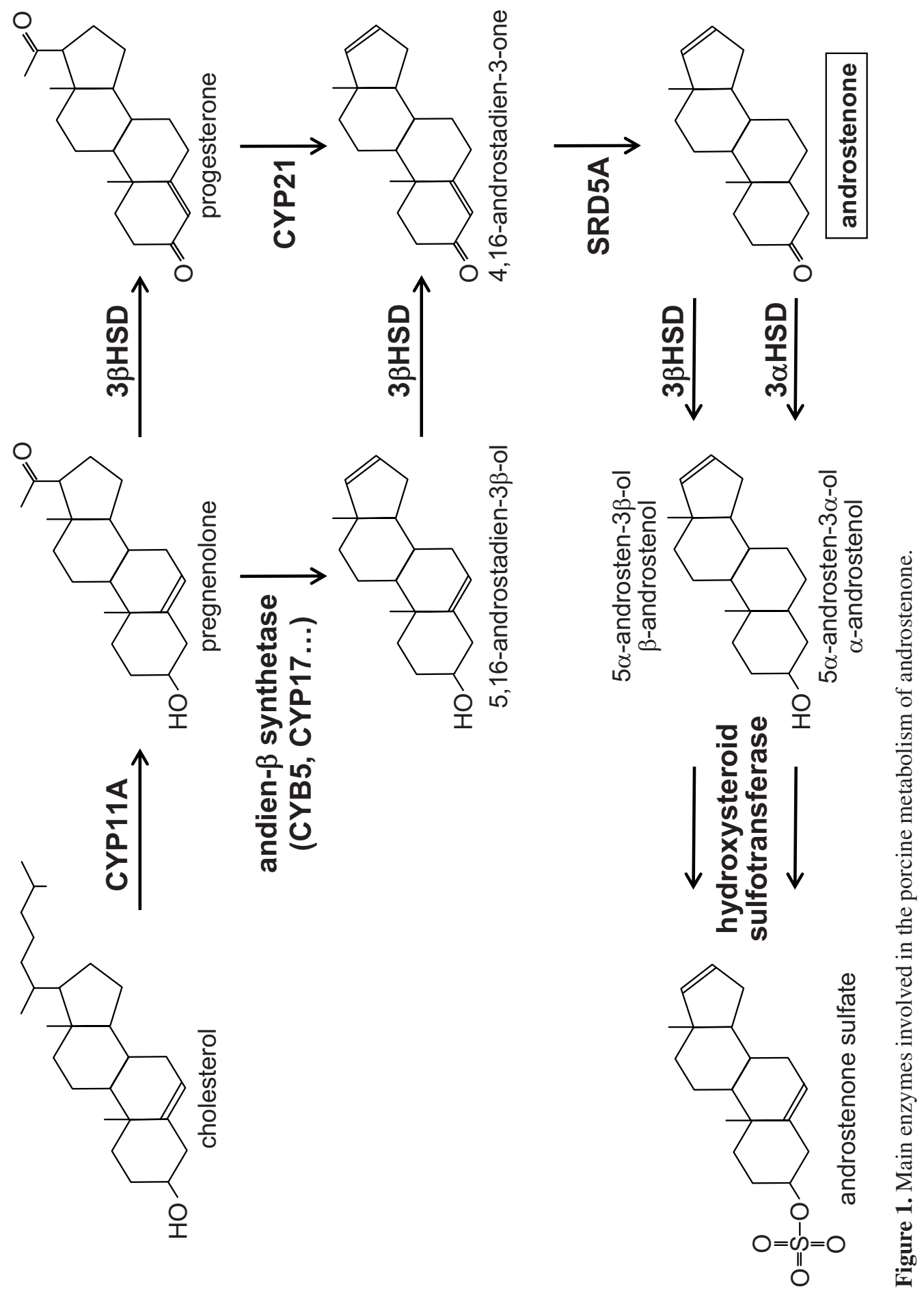
and has been mapped to SSC7 at a location different from that of the QTL characterized on this chromosome [33]. CYP11Al can therefore be excluded as a candidate gene for this QTL. Moreover, the mutation proposed by Greger [17] in the regulatory region of this gene has been excluded as an explanation of the variation of androstenone levels in fat [33].

The formation of 16-androstene steroids from pregnenolone is catalysed by the andien- $\beta$ synthetase enzyme system [19] and CYB5 is the major component of this system (Fig. 1). High levels of CYB5 have been indicated as one of the causes of overproduction of 16-androstene steroids by the testis [11]. The mRNA of porcine CYB5 has been sequenced (Tab. I) and a SNP at base 8 upstream of the ATG in the CYB5 5'UTR has been identified [24]. This SNP is associated with a significant decrease in $C Y B 5$ protein expression (in vitro demonstration) and a low level of androstenone in the fat of animals from a variety of European breeds [24]. The putative location of CYB5 in the porcine genome (Tab. I) excludes this gene as a candidate gene for previously identified androstenone QTL [21,32,33] but CYB5 is most likely a target gene for regulations, which remain to be determined.

Other genes encoding enzymes well known for their involvement in steroidogenesis have also been investigated to identify mutations affecting the synthesis of androstenone in testis. CYP17 and CYP21 are cytochrome P450 enzymes (Fig. 1). No non-synonymous mutation has been detected in the coding sequence of the CYP21 gene located in the region of the androstenone QTL on SSC7 [33]. The CYP17 gene has been tested but without success [25].

\subsection{Genes involved in the degradation of androstenone}

Doran et al. [14] have identified the initial reaction in the metabolism of androstenone in pig liver microsomes: androstenone is reduced by the enzyme $3 \beta-H S D$, mainly to $\beta$-androstenol (Fig. 1). The expression of $3 \beta-H S D$ protein, which is lower in liver microsomes from Meishan pigs (exhibiting high levels of androstenone) than from Large White pigs (exhibiting low levels of androstenone in fat), is accompanied by a reduced level of the corresponding mRNA [29]. This result suggests a defective regulation of the hepatic $3 \beta-H S D$ expression at the transcription level [29]. Although $3 \beta-H S D$ is active in both liver and testis, only expression of the hepatic form is negatively correlated with androstenone levels in fat [29]. In pig, a single gene $H S D 3 B$, encodes this enzyme (Tab. I) and its expression is regulated by a tissue-specific mechanism [29]. This gene is expected to be localized between 90 and $100 \mathrm{cM}$ on the linkage map of SSC4, near the region where a QTL has been detected 
for androstenone level in fat (105 cM by Lee et al. [21]). The HSD3B gene has been entirely sequenced including the promoter. Variations detected in the promoter sequences of the porcine $H S D 3 B$ do not show any relationship with the level of androstenone in fat, but are breed-dependent [10]. It can be speculated that transcription factors responsible for the liver-specific regulation of the expression of $H S D 3 B$ may play an important role in regulating the deposition of androstenone in pig adipose tissue.

Hydroxysteroid sulfotransferase (SULT2A) is responsible for sulfoconjugating the 16-androstene steroids in the liver [37] and testis [39] (Fig. 1). According to Sinclair and Squires [38], a decreased testicular ability to sulfoconjugate androstenone would result in increased levels of unconjugated androstenone in plasma, permitting the accumulation of androstenone in fat. Sinclair et al. [40] have demonstrated that the testicular activity of the enzyme SULT2A is negatively correlated to fat androstenone levels in Yorkshire boars. The expected porcine location of the gene (SSC6, near $80 \mathrm{cM}$ ) is too distant from the androstenone QTL characterized on this chromosome [21]. Although the sequence of the porcine SULT2A promoter is unavailable, an indirect study [40] has shown that nuclear receptors are involved in the regulation of porcine SULT2A. Moreover, the number of genes coding for SULT2A porcine enzyme is currently unknown.

\section{GENES INVOLVED IN THE METABOLISM OF SKATOLE}

Skatole or 3-methyl indole is a derivative of tryptophan produced in the hindgut of pigs by intestinal bacteria. The level of skatole intestinal production is mainly dependent on nutritional factors [18] and no genetic control has been demonstrated so far. This compound is a pneumotoxin in several mammalian species including goats, cattle and man [52] but not in pigs. No physiological function of skatole is known in pigs. Pigs are not sensitive to skatole toxicity, suggesting that they metabolise skatole differently from other species. Phase I of skatole metabolism involves enzymes of the cytochrome P450 family [1] and phase II a sulfoconjugation.

\subsection{Phase I metabolism}

The role of different cytochrome P450 enzymes in skatole metabolism has been investigated by Diaz and Squires [12] who have demonstrated the important role of $C Y P 2 A$ and $C Y P 2 E 1$. Terner et al. [47] have ascribed the major role to $C Y P 2 E 1$. 
Hepatic cytochrome P450 2E1 (CYP2E1) is a microsomal enzyme, which is mainly involved in the metabolism of a number of low molecular weight xenobiotics (ethanol, pyridine, acetone...). In porcine liver, CYP2E1 has an additional important role in catalysing the first step of skatole degradation and a defective hepatic skatole metabolism will lead to skatole accumulation in fat. Low skatole levels in fat have been associated with high levels of CYP2E1 in animals obtained from F4 wild pig crosses (but not in Swedish Yorkshire pigs) $[13,43]$. Skinner et al. [41] have shown an association between a SNP in the promoter region of CYP2E1 gene and skatole deposition in a population of commercial pigs. Lin et al. [26] have characterized a substitution in the CYP2E1 gene causing a significant decrease in the expression and functional activity of CYP2E1 in the liver. No QTL for skatole has been characterized around the location of CYP2E1 (near $110 \mathrm{cM}$ on SSC14 [41]), therefore it is unlikely that this mutation plays a major role in boar taint. However, a better understanding of the regulation of the expression of this gene might help to identify other candidate genes [13]. Tambyrajah et al. [46] have exploited the recent sequencing of the 5' flanking region of the CYP2E1 gene to characterize factors regulating the $C Y P 2 E 1$ promoter activity. They have demonstrated that in pig, binding of two transcription factors (HNF-1 and COUP-TF1) to $C Y P 2 E 1$ could activate the promoter. The regulation of the expression of hepatic $C Y P 2 E 1$ by $H N F-1$ has previously been shown in mice [7] but the activation of the CYP2E1 promoter by COUP-TF1 is a novel observation, which may be specific to the pig species. In man, targeted disruption of the $H N F-1 \alpha$ gene leads to a decreased expression of CYP2E1 [28]. Further research is needed to investigate the polymorphism of the two HNF-1 $\alpha$ genes, TCF 1 and TCF2. TCF 1 is expected to be located in the pig genome near the position $35 \mathrm{cM}$ on the linkage map of SSC14, which is compatible with a QTL for sensory assessed skatole, found by Lee et al. [21].

It has been shown that $C Y P 2 A$ enzymes are involved in the metabolism of skatole in liver $[12,47]$. The relationship between gene polymorphism and skatole levels has been investigated by Lin et al. [22] using a sequence named CYP2A6. However, the corresponding porcine protein shares more similarities with the human protein encoded by CYP2A13 gene than with CYP2A6. To date, the number of genes coding for $C Y P 2 A$ porcine enzymes is not known. The same authors [22] have found that a single base deletion causing a frame shift in the coding region produces a non-functional enzyme. This polymorphism has been characterized in European breeds but could not be identified in Large White $\times$ Meishan crosses [42]. Moreover, the expected location 
of $C Y P 2 A$ on the porcine linkage map i.e. SSC6 at position $70 / 80 \mathrm{cM}$ is not compatible with that of the skatole QTL characterized by Lee et al. [21].

Terner et al. [47] have suggested that P450 cytochromes other than the $C Y P 2 A$ and $C Y P 2 E 1$ enzymes could be involved in the degradation of skatole. Analysis of the porcine CYP2C18 gene encoding another enzyme of the cytochrome P450 family and localized on SSC14 has been carried out but the detected sequence variations did not show any relationship with fat skatole levels in pigs from a Danish commercial population [42] (hybrids Landrace/Yorkshire/ Duroc).

\subsection{Phase II metabolism}

Involvement of sulfation in phase II of the liver catabolism of skatole has been first described by Babol et al. [2], who have demonstrated that sulfation by phenol sulfotransferase (SULT1A) is a major step of skatole clearance. The number of genes coding for the SULT1A porcine enzyme (see Tab. I) is currently not known. A study by Lin et al. [23] with 69 intact male pigs from a variety of European breeds has shown that a polymorphism in the SULT1A gene (Tab. I) causes a significant decrease in its sulfation activity and might be, at least partially, responsible for higher skatole levels. This mutation has been found neither in Large White $\times$ Meishan crosses nor in a Danish commercial population [42]. Moreover its location on SSC3 is incompatible with any identified skatole or indole QTL [42].

\section{RELATIONSHIP BETWEEN ANDROSTENONE AND SKATOLE LEVELS}

Skatole levels in the fat of intact males increase at puberty and are correlated with fat androstenone levels [2,3]. A first hypothesis to account for this observation is that male sex hormones increase skatole production [9]. However, a second hypothesis considering that androgens inhibit the catabolism of skatole has been more widely investigated [13]. Tambyrajah et al. [46] have proposed that regulation mechanisms acting on the promoter of the CYP2E1 gene are very important to explain the variability of skatole level in fat. They have shown that androstenone can inhibit the binding of COUP-TF1 to the promoter of the CYP2E1 gene. Since COUP-TF1 is a member of the steroid hormone receptor family, it is not surprising that androstenone associates with it. In addition, Zamaratskaia et al. [53] have recently shown by other in vitro studies the inhibitory effect of androstenone on CYP2E1 activity, but with concentrations very different from those present in vivo. 


\section{CONCLUSION AND PERSPECTIVES}

In this paper, we have discussed androstenone and skatole metabolisms as equivalent processes. It is important to recall that metabolization of skatole is necessary to eliminate xenobiotic substrates whereas storage of androstenone is biologically important for reproduction function. Understanding the mechanisms of accumulation of these two products has been investigated with a similar interest but their impact on selection is probably different.

Mapping data of QTL involved in boar taint demonstrate its multifactorial nature. Currently, no clear conclusion can be drawn from the whole genome studies on QTL locations for androstenone and skatole levels. The detection of these QTL has been carried out using a whole genome scan approach with microsatellite markers but without further fine mapping. With the currently available tools, a new whole genome scan with a dense panel of SNP markers could permit the fine mapping of QTL. QTL identifications have been performed on an F2 generation of Large White $\times$ Meishan crossed populations [21,33]. All Meishan alleles except that on SSC7 are associated with a high level of androstenone in backfat. Identification of the gene responsible for the QTL on SSC7 will require the production of specific backcrosses to isolate this QTL in a different genetic background. Moreover, it would be very interesting to characterize this QTL in other breeds. QTL studies in pigs at different ages unnecessarily add extra complexity, which may be due to the effect of sexual maturity. Moreover, in many published studies of candidate genes, it is not clear if sexual maturity has been evaluated.

The search for mutations in genes involved in the metabolism of androstenone and skatole has not been very successful in identifying candidate genes responsible for the QTL characterized on Large White $\times$ Meishan crossed populations. This could be explained by the dramatic effect of breed on the incidence of boar taint leading to the fixation of some loci affecting boar taint in certain populations. Moreover, many of the studies on candidate genes involve a very small number of animals. Nevertheless mutations have been found in some genes, which could explain a minor part of the phenotype or restricted to a limited population. Their possible involvement as candidate genes does not exclude them as target genes. The functional investigation of these two metabolic pathways should permit the identification of genes, which act in regulation mechanisms, the most obvious being the regulation of their transcription. Candidate genes will be searched for among genes coding for these transcription factors.

In the next years, the use of microarrays to identify differentially expressed genes associated with the accumulation of androstenone or skatole in fat 
should result in the identification of new target genes. The approach could be similar to that of Stewart et al. [44] who has demonstrated using a human microarray that genes well-known for their involvement in steroidogenesis are over expressed in the testis of pigs with high testicular steroidogenesis. The near availability of the entire porcine sequence will make it possible to analyze all target promoters. It will also be necessary to identify the molecular regulations of these genes. Previous studies have shown which relevant organs should be chosen i.e. testis and liver but the sorting and the choice of relevant animals remain delicate.

The identification of genes involved in a QTL remains a difficult task but in the case of boar taint, it has proven a really complex and complete exercise. It will probably require the fine mapping of QTL and the characterization of QTL on a larger panel of breeds. Although very useful, it is most probable that molecular approaches cannot provide the whole answer. At present, the challenge is to integrate all available strategies on the same animals.

\section{REFERENCES}

[1] Babol J., Squires E.J., Lundstrom K., Hepatic metabolism of skatole in pigs by cytochrome P4502E1, J. Anim. Sci. 76 (1998) 822-828.

[2] Babol J., Squires E.J., Lundstrom K., Relationship between oxidation and conjugation metabolism of skatole in pig liver and concentrations of skatole in fat, J. Anim. Sci. 76 (1998) 829-838.

[3] Babol J., Squires E.J., Lundstrom K., Relationship between metabolism of androstenone and skatole in intact male pigs, J. Anim. Sci. 77 (1999) 84-92.

[4] Bidanel J.P., Riquet J., Gruand J., Squires E.J., Bonneau M., Milan D., Detection of quantitative trait loci for skatole and indole levels in Meishan $\times$ Large White F2 Pigs, 8th WCGALP, August 13-18 2006, Belo Horizonte, Brazil.

[5] Bonneau M., Boar taint in entire male pigs-a review, Pig News Inf. 18 (1997) $15-18$.

[6] Brooks R.I., Pearson A.M., Steroid hormone pathways in the pig, with special emphasis on boar odor: a review, J. Anim. Sci. 62 (1986) 632-645.

[7] Cheung C., Akiyama T.E., Kudo G., Gonzalez F.J., Hepatic expression of cytochrome P450s in hepatocyte nuclear factor 1-alpha (HNF1alpha)-deficient mice, Biochem. Pharmacol. 66 (2003) 2011-2020.

[8] Claus R., [Mammalian pheromones with special reference to the boar taint steroid and its relationship to other testicular steroids (author's transl.)], Fortschr. Tierphysiol. Tierernahr. 10 (1979) 1-136.

[9] Claus R., Weiler U., Herzog A., Physiological aspects of androstenone and skatole formation in the boar - a review with experimental data, Meat Sci. 38 (1994) 289-305. 
[10] Cue R.A., Nicolau-Solano S.I., McGivan J.D., Wood J.D., Doran O., Breedassociated variations in the sequence of the pig 3 $\beta$-hydroxysteroid dehydrogenase gene, J. Anim. Sci. 85 (2007) 571-576.

[11] Davis S.M., Squires E.J., Association of cytochrome b5 with 16-androstene steroid synthesis in the testis and accumulation in the fat of male pigs, J. Anim. Sci. 77 (1999) 1230-1235.

[12] Diaz G.J., Squires E.J., Metabolism of 3-methylindole by porcine liver microsomes: responsible cytochrome P450 enzymes, Toxicol. Sci. 55 (2000) 284-292.

[13] Doran E., Whittington F.W., Wood J.D., McGivan J.D., Cytochrome P450IIE1 (CYP2E1) is induced by skatole and this induction is blocked by androstenone in isolated pig hepatocytes, Chem. Biol. Interact. 140 (2002) 81-92.

[14] Doran E., Whittington F.M., Wood J.D., McGivan J.D., Characterisation of androstenone metabolism in pig liver microsomes, Chem. Biol. Interact. 147 (2004) 141-149.

[15] Fouilloux M.N., Le Roy P., Gruand J., Renard C., Sellier P., Bonneau M., Support for single major genes influencing fat androstenone level and development of bulbo-urethral glands in young boars, Genet. Sel. Evol. 29 (1997) 357-366.

[16] Gower D.B., 16-Unsaturated C 19 steroids. A review of their chemistry, biochemistry and possible physiological role, J. Steroid Biochem. 3 (1972) 45-103.

[17] Greger D., Genetic marker for meat quality, growth, carcass and reproductive traits in livestock, patent WO 0/69882, Washington, DC (2000).

[18] Jensen M.T., Cox R.P., Jensen B.B., 3-Methylindole (skatole) and indole production by mixed populations of pig fecal bacteria, Appl. Environ. Microbiol. 61 (1995) 3180-3184.

[19] Katkov T., Gower D.B., The biosynthesis of androst-16-enes in boar testis tissue, Biochem. J. 117 (1970) 533-538.

[20] Kwan T.T., Orengo C., Gower D.B., Biosynthesis of androgens and pheromonal steroids in neonatal porcine testicular preparations, FEBS letters 183 (1985) 359-364.

[21] Lee G.J., Archibald A.L., Law A.S., Lloyd S., Wood J., Haley C.S., Detection of quantitative trait loci for androstenone, skatole and boar taint in a cross between Large White and Meishan pigs, Anim. Genet. 36 (2005) 14-22.

[22] Lin Z., Lou Y., Squires E.J., Molecular cloning, expression and functional characterization of the cytochrome P450 2A6 gene in pig liver, Anim. Genet. 35 (2004) 314-316.

[23] Lin Z., Lou Y., Squires E.J., Molecular cloning and functional analysis of porcine SULT1A1 gene and its variant: a single mutation SULT1A1 causes a significant decrease in sulfation activity, Mamm. Genome 15 (2004) 218-226.

[24] Lin Z., Lou Y., Peacock J., Squires J.E., A novel polymorphism in the 5' untranslated region of the porcine cytochrome b5 (CYB5) gene is associated with decreased fat androstenone level, Mamm. Genome 16 (2005) 367-373.

[25] Lin Z., Lou Y., Squires E.J., Identification of a single nucleotide polymorphism in porcine testis cytochrome P450-c17 (CYP17) and its effect on steroidogenesis, Biochem. Genet. 43 (2005) 531-542. 
[26] Lin Z., Lou Y., Squires E.J., Functional polymorphism in porcine CYP2E1 gene: Its association with skatole levels, J. Steroid Biochem. Mol. Biol. 99 (2006) 231-237.

[27] Lundström K., Malmfors B., Stern S., Rydhmer L., Eliasson-Selling L., Mortensen A.B., Mortensen H.P., Skatole levels in pigs selected for high lean tissue growth rate on different dietary protein levels, Livest. Prod. Sci. 38 (1994) 135-132.

[28] Maher J.M., Slitt A.L., Callaghan T.N., Cheng X., Cheung C., Gonzalez F.J., Klaassen C.D., Alterations in transporter expression in liver, kidney, and duodenum after targeted disruption of the transcription factor HNF1 $\alpha$, Biochem. Pharmacol. 72 (2006) 512-522.

[29] Nicolau-Solano S.I., McGivan J.D., Whittington F.M., Nieuwhof G.J., Wood J.D., Doran O., Relationship between the expression of hepatic but not testicular $3 \beta$-hydroxysteroid dehydrogenase with androstenone deposition in pig adipose tissue, J. Anim. Sci. 84 (2006) 2809-2817.

[30] Patterson R.L.S., 5a-androst-16-ene-3-one, compound responsible for taint in boar fat, J. Sci. Food Agric. 19 (1968) 31-38.

[31] Pedersen B., Heritability of skatole in back fat, in: Jensen W.K. (Ed.), Skatole and boar taint, Roskilde, Denmark, Danish Meat Research Institute (1998) 129-136.

[32] Quintanilla R., Milan D., Bidanel J.P., A further look at quantitative trait loci affecting growth and fatness in a cross between Meishan and Large White pig populations, Genet. Sel. Evol. 34 (2002) 193-210.

[33] Quintanilla R., Demeure O., Bidanel J.P., Milan D., Iannuccelli N., Amigues Y., Gruand J., Renard C., Chevalet C., Bonneau M., Detection of quantitative trait loci for fat androstenone levels in pigs, J. Anim. Sci. 81 (2003) 385-394.

[34] Robic A., Faraut T., Iannuccelli N., Lahbib-Mansais Y., Cantegrel V., Alexander L., Milan D., A new contribution to the integration of human and porcine genome maps: 623 new points of homology, Cytogenet. Genome Res. 102 (2003) 100-108.

[35] Sellier P., Genetics of meat and carcass traits, in: Rothschild M.F., Ruvinsky A. (Eds.), The Genetics of the Pig, CAB International, Wallingford, Oxon, UK, 1998, pp. 463-510.

[36] Sellier P., Le Roy P., Fouilloux M.N., Gruand J., Bonneau M., Responses to restricted index selection and genetic parameters for fat androstenone level and sexual maturity status of young boars, Livest. Prod. Sci. 63 (2000) 265-274.

[37] Sinclair P.A., Hancock S., Gilmore W.J., Squires E.J., Metabolism of the 16androstene steroids in primary cultured porcine hepatocytes, J. Steroid Biochem. Mol. Biol. 96 (2005) 79-87.

[38] Sinclair P.A., Squires E.J., Testicular sulfoconjugation of the 16-androstene steroids by hydroxysteroid sulfotransferase: its effect on the concentrations of $5 \alpha$-androstenone in plasma and fat of the mature domestic boar, J. Anim. Sci. 83 (2005) 358-365.

[39] Sinclair P.A., Squires E.J., Raeside J.I., Renaud R., Synthesis of free and sulphoconjugated 16-androstene steroids by the Leydig cells of the mature domestic boar, J. Steroid Biochem. Mol. Biol. 96 (2005) 217-228. 
[40] Sinclair P.A., Gilmore W.J., Lin Z., Lou Y., Squires E.J., Molecular cloning and regulation of porcine SULT2A1: relationship between SULT2A1 expression and sulfoconjugation of androstenone, J. Mol. Endocrinol. 36 (2006) 301-311.

[41] Skinner T.M., Doran E., McGivan J.D., Haley C.S., Archibald A.L., Cloning and mapping of the porcine cytochrome-p450 2E1 gene and its association with skatole levels in the domestic pig, Anim. Genet. 36 (2005) 417-422.

[42] Skinner T.M., Anderson J.A., Haley C.S., Archibald A.L., Assessment of SULT1A1, CYP2A6 and CYP2C18 as candidate genes for elevated backfat skatole levels in commercial and experimental pig populations, Anim. Genet. 37 (2006) 521-522.

[43] Squires E.J., Lundstrom K., Relationship between cytochrome P450IIE1 in liver and levels of skatole and its metabolites in intact male pigs, J. Anim. Sci. 75 (1997) 2506-2511.

[44] Stewart J.D., Lou Y., Squires E.J., Coussens P.M., Using human microarrays to identify differentially expressed genes associated with increased steroidogenesis in boars, Anim. Biotechnol. 16 (2005) 139-151.

[45] Tajet H., Andresen O., Meuwissen T.E., Estimation of genetic parameters for boar taint: skatole and androstenone and their correlations with sexual maturation., Acta Vet. Scand. 48 (Suppl. 1) S9 (2006) 22-23.

[46] Tambyrajah W.S., Doran E., Wood J.D., McGivan J.D., The pig CYP2E1 promoter is activated by COUP-TF1 and HNF-1 and is inhibited by androstenone, Arch. Biochem. Biophys. 431 (2004) 252-260.

[47] Terner M.A., Gilmore W.J., Lou Y., Squires E.J., The role of CYP2A and CYP2E1 in the metabolism of 3-methylindole in primary cultured porcine hepatocytes, Drug Metab. Dispos. 34 (2006) 848-854.

[48] Varona L., Vidal O., Quintanilla R., Gil M., Sanchez A., Folch J.M., Hortos M., Rius M.A., Amills M., Noguera J.L., Bayesian analysis of quantitative trait loci for boar taint in a Landrace outbred population, J. Anim. Sci. 83 (2005) 301-307.

[49] Vold E., Fleishprouktionseigenschaften bei Ebern und Kastraten: IV. Organoleptische und gaschromatografische untersuchungen wasserdampffluchtiger stoffe des ruckenpeckes von ebern, Meldinger fra Norges Landbrukshogskole 49 (1970) 1-25.

[50] Weiler U., Font Furnols M., Fischer K., Kemmer H., Oliver M.A., Gispert M., Dobrowolski A., Claus R., Influence of differences in sensitivity of Spanish and German consumers to perceive androstenone on the acceptance of boar meat differing in skatole and androstenone concentrations, Meat Sci. 54 (2000) 297-304.

[51] Wysocki C.J., Beauchamp G.K., Ability to smell androstenone is genetically determined, Proc. Natl. Acad. Sci. USA 81 (1984) 4899-4902.

[52] Yost G.S., Mechanisms of 3-methylindole pneumotoxicity, Chem. Res. Toxicol. 2 (1989) 273-279.

[53] Zamaratskaia G., Gilmore W.J., Lundstrom K., Squires E.J., Effect of testicular steroids on catalytic activities of cytochrome $\mathrm{P} 450$ enzymes in porcine liver microsomes, Food Chem. Toxicol. 45 (2007) 676-681. 